\title{
Announcement of 2010-2011, Rose Marie Pangborn, Sensory Science Scholarship
}

(C) 2010 Springer Science+Business Media, LLC

One $\$ 14,000$ Sensory Science Scholarship will be awarded for the 2010-2011 academic year to support a Ph.D. student who intends to teach and conduct research in the area of sensory science at the University level. This scholarship is awarded in honor of the memory of Professor Rose Marie Pangborn who initiated the scholarship fund to encourage the education of Sensory Scientists intending to pursue academic careers.

Applicants for the scholarship must be enrolled in a $\mathrm{Ph}$. D. Program such as Food Science, Nutrition, Psychology, or Physiology. The planned or on-going dissertation research must be on a sensory topic under the guidance of a sensory scientist. Candidates will be evaluated on the basis of their academic record, intended research in human sensory science, commitment to a career in teaching in the field of sensory science, and support determined by letters of recommendation. The Board of Directors of the Sensory
Science Scholarship Fund (SSSF) will determine policies governing the award and will select recipients.

Applications, including all required documentation, must be postmarked no later than May 1, 2010. For additional information and application forms, contact Dr. Rick Mattes, Purdue University, Department of Foods and Nutrition, 700W. State St., W. Lafayette, IN 47907-2059, USA Phone: 765-494-0662; FAX: 765-494-0674; email: mattes@purdue.edu Application forms are also downloadable at http://www.cfs.purdue.edu/sssf/.

Past recipients include: Michael Nestrud, Karen Ann Lusk (Hein), Gaston Ares, Martha Bajec, John Hayes, Derek Snyder, Cheryl Armstrong, Zuzana Drobna, Terri Rosett, Nicolette van der Klaauw, Sophie Bonnans, Jeannine Delwiche, Liz Gwartney, Thomas Heinbockel, Andrew Smith, Barbara Guggenbühl, Elba Cubero-Castillo, Randy Lee, and Lotika Bhatia Savant. 